\title{
Cloning and Characterization of a Constitutive Lysophosphatidic Acid Acyltransferase 2 (LPAT2) Gene from Tropaeolum majus $\mathrm{L}$
}

\author{
David C. Taylor*, Tammy Francis, Sharla Lozinsky, Travis Hoffman, Mike Giblin and \\ Elizabeth-France Marillia
}

\begin{abstract}
National Research Council of Canada, Plant Biotechnology Institute, 110 Gymnasium Place, Saskatoon, SK, Canada, S7N $0 W 9$
\end{abstract}

\begin{abstract}
The cloning and characterization of a lyso-phosphatidic acid acyltransferase (LPAT2; EC 2.3.1.51) from Tropaeolum majus from a 20,000 EST collection is described. The 1358 bp TmLPAT2 gene encodes a $42.6 \mathrm{kD}$ polypeptide; the primary sequence has a membrane bound $O$-acyltransferase, MBOAT, Box I motif, and Boxes II, III and IV typical of LPATs from various species. Unlike many LPAT2s, the gene was constitutively expressed in all tissues. The TmLPAT2 functionality was confirmed by expression in a yeast LPAT deletion ( $\mathrm{SLCl}$ ) mutant. The TmLPAT2 could use a range of acyl-CoAs as acyl donor, including 22:1-CoA and 20:1-CoA and either 18:1-LPA or 22:1-LPA as acyl acceptor. This new LPAT2 could enable the production of Brassica seed oils with enhanced levels of very long-chain fatty acids.
\end{abstract}

Keywords: Tropaeolum majus, LPAT, lyso-phosphatidic acid acyltransferase, erucic acid, triacylglycerol, yeast.

\section{INTRODUCTION}

Many groups worldwide have a vested interest in inserting genes into Brassica napus in an effort to produce the industrial feedstock trierucin. Erucic acid (cis-13 docosenoic acid, 22:1) is the major very long-chain fatty acid (VLCFA) in the seed oil from HEAR (high erucic acid rapeseed) $B$. napus cultivars, accounting for $45-55 \%$ of the total fatty acids [1]. HEAR cultivars are of high interest for industrial purposes because $22: 1$ is a valuable feedstock with more than 1000 potential or patented industrial applications [2,3]. Currently the major derivative of erucic acid is erucamide, which is used as a surface-active additive in coatings and in the production of plastic films as an anti-block or slip promoting agent. Many other applications are foreseen for erucic acid and its hydrogenated derivative behenic acid, e.g. in lubricants, detergents, film processing agents and coatings, as well as in cosmetics and pharmaceuticals [4-7]. For many of these industrial uses, the economics are limited by the proportion of $22: 1$ in the seed oil, approximately $45 \%$. To compete with petroleum-based products, it is desirable to increase the 22:1 proportion as high as possible in order to reduce the cost of purification [3]. In addition, the engineering of HEAR Brassicaceae to produce seed oils containing substantial trierucin would lend the intact oil to a wide range of new applications [2]. In general, stereospecific analyses have shown that among most members of the Brassicaceae, 22:1 is virtually excluded from the $s n-2$ position of TAGs [8]; thus erucic acid is essentially found only in the $s n-3$ and the $s n-1$ positions, limiting the overall proportions of $22: 1$ to a maximum of about $66 \mathrm{~mol} \%$. The best HEAR B. napus

*Address correspondence to this author at the National Research Council of Canada, Plant Biotechnology Institute, 110 Gymnasium Place, Saskatoon, SK, S7N 0W9, Canada; Tel: (306) 975-5268; Fax: (306) 975-4839

E-mail: David.Taylor@nrc-cnrc.gc.ca spring cultivars have only about $55 \%$ erucic acid in the seed oil, but again, the proportion in the $s n-2$ position is negligible [7].

In the traditional Kennedy pathway for seed oil (triacylglycerol, TAG) biosynthesis, lyso-phosphatidic acid acyltransferase (LPAT; EC 2.3.1.51) is the major enzyme responsible for acylating the $s n-2$ position of the glycerol backbone and therefore largely determines the $s n-2$ acyl composition of TAGs $[9,10]$. This presumably ER-based LPAT is typically referred to as an LPAT2 in most oilseed species, distinguishing it from the plastidial LPAT1 which has enzyme characteristics more like the prokaryotic LPAT found in E. coli (See overview by Kim et al., [11]).

Several studies have suggested that in B. napus the limitation with respect to erucic acid proportions at the $s n-2$ position is at least partially due to the inability of the LPAT2 to utilize erucoyl-CoA [12-15]. Various groups worldwide have attempted or advocated the transformation of rapeseed with an LPAT2 gene which has the desired capacity to utilize erucoyl-CoA during TAG bioassembly [14-19]. LPAT2s from Limnanthes spp appear to be capable of inserting erucoyl moieties into the $s n-2$ position. While the overall proportions of erucic acid in the seed oil of Limnanthes is only about $16 \%$, of this, about $60 \%$ is found in the $s n-2$ position [14-19]. Accordingly, LPAT2s from L. douglasii and L. alba have been cloned and used to enhance $s n-2$ erucic proportions in $B$ napus [20-22] but with this single genetic modification, the enhancement of overall proportions of erucic acid and accumulation of significant trierucin have not resulted [23]. Indeed, the erucic acid was merely redistributed from the $s n-1$ and $s n-3$ positions to the $s n-2$ position, with no significant improvement in the mol \% erucic acid in seed TAGs. This suggested, that in part, erucic acid supply was a limiting factor. Recently it has been shown that by combin- 
ing alleles of $B$. napus related to low polyunsaturated oils with the transgenic co-expression of the L. douglasii LPAT2 and over-expression of the BnFAE1 (encoding 3-ketoacylCoA synthase, catalyzing the first condensation reaction in the elongase complex which synthesizes erucic acid), a $B$. napus line with oil containing just over $70 \%$ erucic acid was obtained, clearly a breakthrough [24].

The only species so far identified that naturally possesses erucic acid proportions of $75 \%$ or greater, mainly as trierucin, in its seed oil is garden nasturtium (Tropaeolum majus L.). Nasturtium is not an oilseed per se, accumulating only about $10-20 \%$ oil, but of this, $80-85 \%$ is trierucin. Thus, we chose $T$. majus as a model system for studying trierucin bioassembly so that this capacity could be engineered in a Brassica oilseed. It was in this context that we undertook the task of creating an EST collection of T. majus sequences in an effort to isolate and define specific genes which can contribute to trierucin synthesis. These nasturtium genes may provide a means to engineer rapeseed and other Brassica oilseeds to produce ultra-high erucic acid ( $80 \%$ or greater) oils. In our analysis of our 20,000-EST collection, we found two overlapping contigs which, when re-assembled, gave us a clone encoding a putative T. majus LPAT2 (TmLPAT2). We describe herein, its isolation and characterization by expression in a yeast $L P A T$ (slc $\Delta)$ deletion strain, and the implications for its utility in engineering new oilseed profiles.

\section{MATERIALS AND METHODS}

\section{Plant Materials and Growth Conditions}

Tropaeolum majus seeds (cultivar Dwarf Cherry Rose) were obtained from Early's Farm and Garden Centre, Saskatoon, SK, and were grown at the Kristjanson Biotechnology Complex greenhouses, Saskatoon, under natural light conditions supplemented with high-pressure sodium lamps with a $16 \mathrm{~h}$ photoperiod (16 h of light and $8 \mathrm{~h}$ of darkness) at $22^{\circ} \mathrm{C}$ and a relative humidity of 25 to $30 \%$. Flowers were handpollinated and seeds at various stages of development were harvested, their seed coats were removed and embryos were frozen in liquid nitrogen and stored at $-80^{\circ} \mathrm{C}$. The lipid composition of developing nasturtium embryos at various stages of development was determined. The following were the designated stages of embryo development in days post anthesis: Early: 8-12 d.p.a.; Early-mid: 13-20 d.p.a.; Mid: 2227 d.p.a.; Mid-late: 27-30 d.p.a.; Mature: 35 d.p.a. Arabidopsis thaliana plants were grown and harvested as described previously [25].

\section{Analysis of Oil Accumulation in Developing Tropaeolum majus Embryos}

Freeze-dried T. majus embryos of early-, mid- and latedevelopmental stages, as well as mature seeds, were weighed and transferred to a cooled mortar and ground in $2 \mathrm{ml}$ $\mathrm{CH}_{2} \mathrm{Cl}_{2}$ :IPA $(2: 1)$. The mixture was transferred to a test tube to which was added the above solvent $(1 \mathrm{ml})$ and $0.9 \% \mathrm{NaCl}$ (1ml) before vortexing; $2 \mathrm{ml} \mathrm{CH}_{2} \mathrm{Cl}_{2}$ was added, the mixture re-vortexed and centrifuged at 2500 r.p.m. for $3 \mathrm{~min}$. The $\mathrm{CH}_{2} \mathrm{Cl}_{2}$ layer was removed, the extraction repeated and the $\mathrm{CH}_{2} \mathrm{Cl}_{2}$ layers combined. $\mathrm{CHCl}_{3}$ : Benzene: Methanol $(1: 1: 1)(1 \mathrm{ml})$ was added and then the sample evaporated to dryness. The dried sample was resuspended in $\mathrm{CHCl}_{3}(1 \mathrm{ml})$ to give the total lipid extract (TLE). The developmental acyl composition of the TLE and the total oil content at each stage were determined by transesterification followed by GC using tri-15:0 as an internal standard and tri-17:0 as an external standard (to determine completeness of transmethylation) as described previously [25]. The T. majus TAG fraction was isolated by TLC and a stereospecific analysis performed as described by Taylor et al., [26].

\section{T. majus cDNA Library Construction and Normalization}

cDNA was synthesized from mRNA isolated from middeveloping nasturtium embryos using a cDNA synthesis kit (Stratagene). The cDNA was directionally cloned into the pBluescript SK II (+) vector (Stratagene) and transformed into DH10B electrocompetent cells. The primary library was amplified using semi-solid agar (SeaPrep agarose, Mandel). Normalization of the library was performed at $\mathrm{C}_{0} \mathrm{t} 2.5$ and $\mathrm{C}_{0} \mathrm{t} 5$ following the normalization method 4 of Bonaldo et al., [27]. Double-stranded phagemid DNA was converted to single stranded DNA using Gene II protein and Exonuclease III (Genetrapper cDNA Positive Selection System, Gibco BRL, cat. no. 10356-020). The single stranded DNA was purified from the double stranded DNA using HAP chromatography (type II Hydroxyapatite, BioRad, cat. no. 1584200). 20,000 ESTs from this library were sequenced as described below.

\section{Sequencing and Analysis}

Sequencing was performed on an ABI3730xl DNA Analyzer using a BigDye Terminator v3.1 Cycle Sequencing kit (Applied Biosystems). Sequence analyses were performed using Lasergene software (DNAStar, Madison, WI, USA). Sequence similarity searches and other analyses were performed using BLASTN, BLASTX [28] and PSORT [29] programs. The T. majus LPAT2 clone was represented by 2 overlapping contig members among 20,000 ESTs isolated and analyzed from a normalized cDNA library prepared from mid-developing nasturtium embryos.

\section{Cloning of Full Length $T$ majus (Tm) and $A$ thaliana (At) $L P A T 2$ cDNAs and Assembly of Yeast Transformation Constructs}

\section{$T m L P A T 2$}

Primers were designed to amplify the TmLPAT2 gene with adaptor restrictions sites (in italics): 5 ' primer amplifying TmLPAT2 sequence with a Kpn I restriction site (GAGGTACCGGAAATGTCAGTTGCAGC); 3' primer amplifying TmLPAT2 sequence (+ stop codon) with an Xho I site (CCGCTCGAGTTTTACTGATGTTTGGTTGC). cDNA was synthesized from total RNA extracted from $T$. majus mid-developing embryos using Superscript II (Invitrogen). The TmLPAT2 gene was amplified from the cDNA using Turbo Pfu polymerase (Stratagene) on a RoboCycler thermocycler (Stratagene) using the following program: $95^{\circ} \mathrm{C}$ for $3 \mathrm{~min}$, followed by 30 cycles of $95^{\circ} \mathrm{C}$ for $30 \mathrm{sec}, 55^{\circ} \mathrm{C}$ for 45 sec, $72^{\circ} \mathrm{C}$ for $2 \mathrm{~min}$, an additional extension of $72^{\circ} \mathrm{C}$ for 10 min was included. The amplified PCR product was digested using restriction enzymes KpnI (NEB) and XhoI (NEB). The PCR-amplified TmLPAT2 was directionally cloned into the 
respective KpnI and XhoI sites of pYES/NT B (Invitrogen) using T4 DNA ligase (Invitrogen) in a 4:1 molar ratio (insert: vector) at $4^{\circ} \mathrm{C}$ overnight. Four microliters of the ligation reaction were used to transform Top 10 Chemically Competent Cells (Invitrogen) as per standard protocols. Putative clones were cultured in liquid medium with ampicillin selection, and grown overnight at $37^{\circ} \mathrm{C}$ with shaking $(250 \mathrm{rpm})$. Plasmid DNA was extracted using a QIAprep Spin miniprep kit (Qiagen). PCR screening for the gene insert was performed using GAL1/V5CR primers and Taq polymerase (Program: $95^{\circ}-3 \mathrm{~min} ; 30$ cycles of $95^{\circ} \mathrm{C}-30 \mathrm{~s}, 52^{\circ} \mathrm{C}-45 \mathrm{~s}$, $72^{\circ} \mathrm{C}-2 \mathrm{~min} ; 72^{\circ} \mathrm{C}-10 \mathrm{~min}$ ). Positive clones were confirmed by sequencing.

\section{At LPAT2}

Primers were designed to amplify the A. thal LPAT2 gene (Accession No. At3g57650) with adaptor restrictions sites (in italics): 5' primer amplifying AtLPAT2 sequence with a Kpn I restriction site (CCGGTACCAGGATGGTGATTGCTGCAGCT); 3' primer amplifying AtLPAT2 sequence (+ stop codon) with an Xho I site CCCTCGAGTGTGAGAACCAGTTTTTACTT). Total RNA was extracted from $A$. thaliana ecotype Columbia leaves using Trizol (Invitrogen) and the cDNA was synthesized and used to amplify the $A$ thaliana LPAT2 as described for the TmLPAT2 above.

\section{Molecular Analyses of the TmLPAT2}

The alignment of the TmLPAT2 with other cloned LPATs shown in Fig. (2) and the phylogenetic tree with bootstrap values (phenogram) shown in Fig. (3), were calculated using the Clustal W method in the Lasergene Megalign analysis software suite (DNAStar, Madison, WI.).

For Southern analysis, total DNA was extracted from $1 \mathrm{~g}$ of T. majus leaves according to Dellaporta et al., [30]. About 15 ug of genomic DNA were digested with restriction enzymes AseI, EcoRI, HindIII and XhoI (NEB) and the fragments separated by agarose gel $(0.7 \%)$ electrophoresis in $1 \mathrm{X}$ TAE buffer. The DNA was blotted onto Amersham Hybond XL (GE Healthcare) membrane using a Turbo Blotter (Whatman) and following the alkaline transfer procedure $(0.4 \mathrm{~N}$ $\mathrm{NaOH}$ ). The Southern probe was amplified by PCR with primers designed to bind to a $450 \mathrm{bp}$ region from the $5^{\prime}$ end of the KCS gene and that would not be cut by the restriction enzymes selected here. Hybridization was carried out in Denhardt's buffer at $65{ }^{0} \mathrm{C}$ for $16 \mathrm{~h}$ using the ${ }^{32} \mathrm{P}$-labeled DNA probe using a Random Primers labeling kit (Invitrogen). High stringency washings were performed at $65^{\circ} \mathrm{C}(2 \mathrm{X}$ 15 min with 2 X SSC $/ 0.1 \%$ SDS and 1 X 15 min with 0.1 X $\mathrm{SSC} / 0.1 \%$ SDS) before exposing to X-ray film (Fuji Medical X-Ray film) at $-80{ }^{\circ} \mathrm{C}$.

In studies of TmLPAT2 expression by northern analysis, total RNA was extracted using either Trizol Reagent (Invitrogen) for root, stem and leaf tissues, or using the method of Wang and Vodkin [31] for flower and embryonic (three developmental stages) tissues. $20 \mu \mathrm{g}$ of each sample were loaded onto a $1.2 \%$ denaturing formaldehyde agarose gel. The RNA was transferred onto a Nytran SuPerCharge membrane in $10 \mathrm{X}$ SSC using a Turbo Blotter (Whatman) and hybridized as above using a full length $T m L P A T$ cDNA as a probe. High stringency washings were performed at $60{ }^{\circ} \mathrm{C}$,
2X 15 min with $40 \mathrm{mM} \mathrm{NaPO} 4 / 1 \mathrm{mM} \mathrm{Na}$ EDTA/0.5\% SDS and 2X 15 min with $40 \mathrm{mM} \mathrm{NaPO} 4 / 1 \mathrm{mM} \mathrm{Na}$ EDTA/0.1\% SDS before exposing to X-rays at $-80^{\circ} \mathrm{C}$.

\section{Transformation of Y03749 Yeast $L P A T$ Deletion Mutant Strain with TmLPAT2 or AtLPAT2}

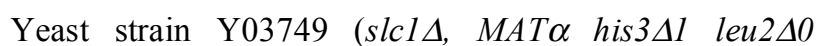
met15 10 ura3 $\Delta 0$ YDL052c::KanMX4) was transformed with the pYES2 NT B-AtLPAT2 or with pYES2 NT B-TmLPAT2 or with empty pYES2 NT B vector using the small scale yeast transformation method from the pYES2 NT B manual. Clones were selected on plates contaning (SC - Uracil $+2 \%$ Glucose).

Transformation was confirmed as follows: DNA from putative positive clones was extracted using a quick plasmid extraction method. A single colony was picked into $200 \mu \mathrm{l}$ lysis buffer $(100 \mathrm{mM} \mathrm{NaCl}, 10 \mathrm{mM}$ Tris-HCL pH8.0, $1 \mathrm{mM}$ EDTA, and $0.1 \%$ SDS). An equal volume of acid-washed beads $(0.5 \mathrm{~mm}$ diameter) was added along with $200 \mu 1$ phenol:choloroform (2:1), the sample vortexed for 30 seconds, followed by slow rotation for 5 minutes to complete the extraction. The mixture was then centrifuged for 5 minutes at $13000 \mathrm{rpm}$. The aqueous phase was recovered and the DNA precipitated using 2 volumes of ethanol and $0.1 \mathrm{x}$ volume of $3 \mathrm{M}$ sodium acetate. The sample was incubated at $-80^{\circ} \mathrm{C}$ for 30 minutes then centrifuged at $13000 \mathrm{rpm}$ for $15 \mathrm{~min}$. The DNA pellet was washed with $80 \%$ ethanol, re-centrifuged at $13,000 \mathrm{rpm}$ for $5 \mathrm{~min}$, the DNA pellet air dried and resuspended in $50 \mu 1 \mathrm{TE}$ buffer. DNA concentration was measured using a NanoDrop ND-1000 spectrophotometer. Top10 Chemically Competent cells (Invitrogen) were transformed with the purified DNA as per a standard protocol. Colonies were screened by PCR and restriction digests.

\section{TmLPAT2 and AtLPAT2 Expression in Y03749 Yeast LPAT (slc $\triangle$ ) Deletion Mutant and Assay of LPAT Activity}

Starter cultures of the Y03749 TmLPAT2, Y03749 AtLPAT2 or Y03749 plasmid only (control) transformants were grown in minimal medium ( $\mathrm{SC}-$ Uracil $+2 \%$ Glucose) at $30^{\circ} \mathrm{C}$ with shaking at $250 \mathrm{rpm}$. Culture density was measured using $\mathrm{OD}_{595}$, and sufficient culture to produce an $\mathrm{OD}_{595}=0.4$ in $50 \mathrm{ml}$ of Induction Medium (SC-Uracil $+2 \%$ Galactose + $1 \%$ Raffinose) was centrifuged, washed and resuspended in Induction Medium. Cultures were induced at $30^{\circ} \mathrm{C}$ with shaking $(250 \mathrm{rpm})$ for $8,16,24$ or $48 \mathrm{hrs}$. The maximum expression of the TmLPAT2 recombinant protein was obtained after a 24 hour induction; the $A t$ LPAT2 expression was maximal at $48 \mathrm{hr}$ of induction. Induced cells were harvested by centrifugation and protein was extracted using the glass bead/bead beater method. Protein concentration was measured in triplicate using Bradford reagent, normalized and the protein was used immediately for the LPAT assay.

LPAT assays of the recombinant protein fraction from each transformant were conducted as described previously [26] using either ${ }^{14} \mathrm{C} 18: 1-\mathrm{CoA}$ or ${ }^{14} \mathrm{C} 22: 1-\mathrm{CoA}$ as the acyl donor and 18:1-LPA or 22:1-LPA as the acyl acceptor. The resolution of the ${ }^{14} \mathrm{C}$-labeled PA product by TLC run in ethyl acetate/iso-octane/acetic acid (45/15/10) was as described by Taylor et al. [26]. 
LPCAT assays of the recombinant protein fraction from each transformant were conducted using ${ }^{14} \mathrm{C}$ 18:1-CoA or ${ }^{14} \mathrm{C} 22: 1-\mathrm{CoA}$ as the acyl donor and 18:1-LPC as the acyl acceptor according to the method described by Stahl et al. [38].

\section{RESULTS AND DISCUSSION}

\section{Oil and Erucic Acid Accumulation in Developing $T$. majus Embryos}

We assumed that, like other Kennedy pathway enzymes (e.g. T. majus DGAT1 which we cloned and characterized previously [32]), the LPAT2 would also be at its highest expression and activity at the mid-point of the exponential phase of embryo growth. For nasturtium, the peak of oil deposition (about $16 \%$ oil as $\%$ of DW) and the maximal erucic acid proportion therein (about $78 \% \mathrm{wt} / \mathrm{wt}$ ), occurred in the mid-late developmental stage, typically 20-26 days post-anthesis (Fig. 1). This was the embryo stage harvested and stored at $-80^{\circ} \mathrm{C}$ for molecular and analytical work.

A stereospecific analysis of the $T$. majus TAG fraction revealed that the erucic acid was distributed about equally among the three $s n$-positions on the glycerol backbone (Table 1). This suggested a strong capacity to esterify erucic acid at the $s n-2$ position and implied that enzymes like LPAT or LPCAT may be involved.

\section{Analysis of the TmLPAT2 Gene}

Upon sequencing and analysis of our 20,000 T. majus ESTs, we found 2 overlapping contigs, which when assembled, gave a sequence which encoded a putative TmLPAT2 gene. The TmLPAT2 gene and protein sequences were deposited in GenBank (Accession No. FJ984563). The consensus TmLPAT2 nucleotide sequence of 1358 bp encodes a protein of 380 amino acids and has a predicted molecular mass of $42.585 \mathrm{kD}$, and a pI of 9.60. Based on a KyteDoolittle analysis using the Protean suite of DNAStar, there appear to be at least 8 transmembrane regions and a hydrophilicity pattern which is globally-shared among the LPAT2s from B. napus, B. oleracea, A. thaliana, Crambe, Prunus and Limnanthes (data not shown).

Alignment and phylogenetic tree assessment of the TmLPAT2 and its most homologous relatives are shown in Fig. (2) and Fig. (3), respectively. Key motifs of the TmLPAT2 primary amino acid sequence as shown in Fig. (2) include: Box I-IV motifs are conserved among related LPAT2s in various plant species [11]. Box $\mathrm{I}$ is a conserved MBOAT motif (NHXXXXD): NHRSDID in position 91 - 97 [33],
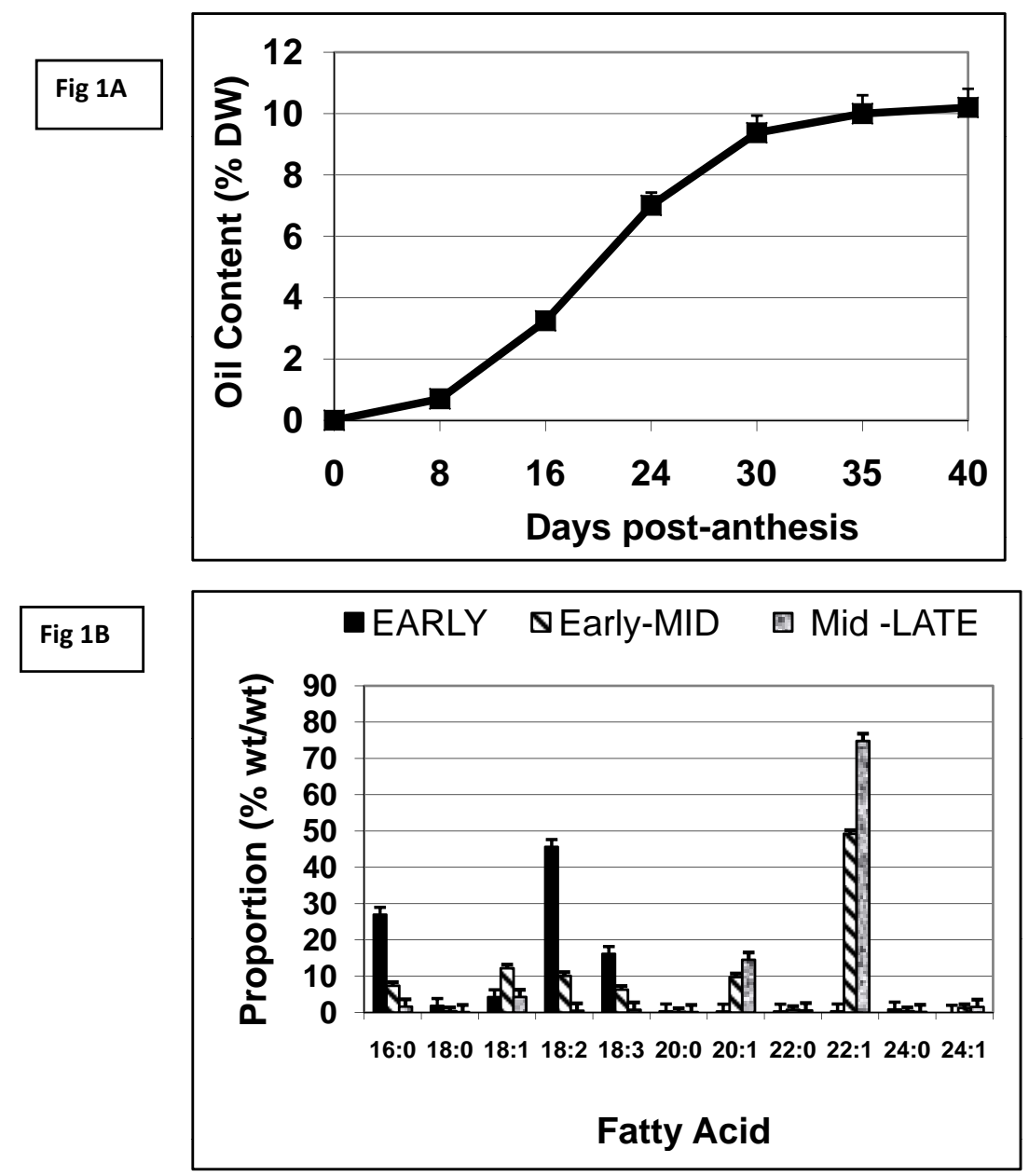

Fig. (1). (A) TAG accumulation in developing T. majus seed. (B) Fatty acid composition of developing T. majus seed. The following were the designated stages of embryo development in days post anthesis: Early: 8-15 d.p.a.; Early-mid: 16-20 d.p.a.; Mid: 22-27 d.p.a.; Mid-late: 27-30 d.p.a.; Mature: 38 d.p.a. Fatty acid composition and oil content were measured as described in the MATERIALS and METHODS and represent the average of three determinations \pm SD. 
Table 1. Stereospecific Distribution of Acyl Moieties on TAGs of $\boldsymbol{T}$. majus. Stereospecific analyses were performed as described by Taylor et al (8). Total TAG reports the acyl composition of the TAG fraction isolated from a total lipid extract. In set A, the distribution of all acyl moieties at each sn-position is reported (read left to right). In set $\mathrm{B}$, the distribution of each acyl moiety over all three $s n$-positions is reported (read top to bottom). The distribution of the VLCMFAs 20:1 and 22:1 are bolded and shaded.

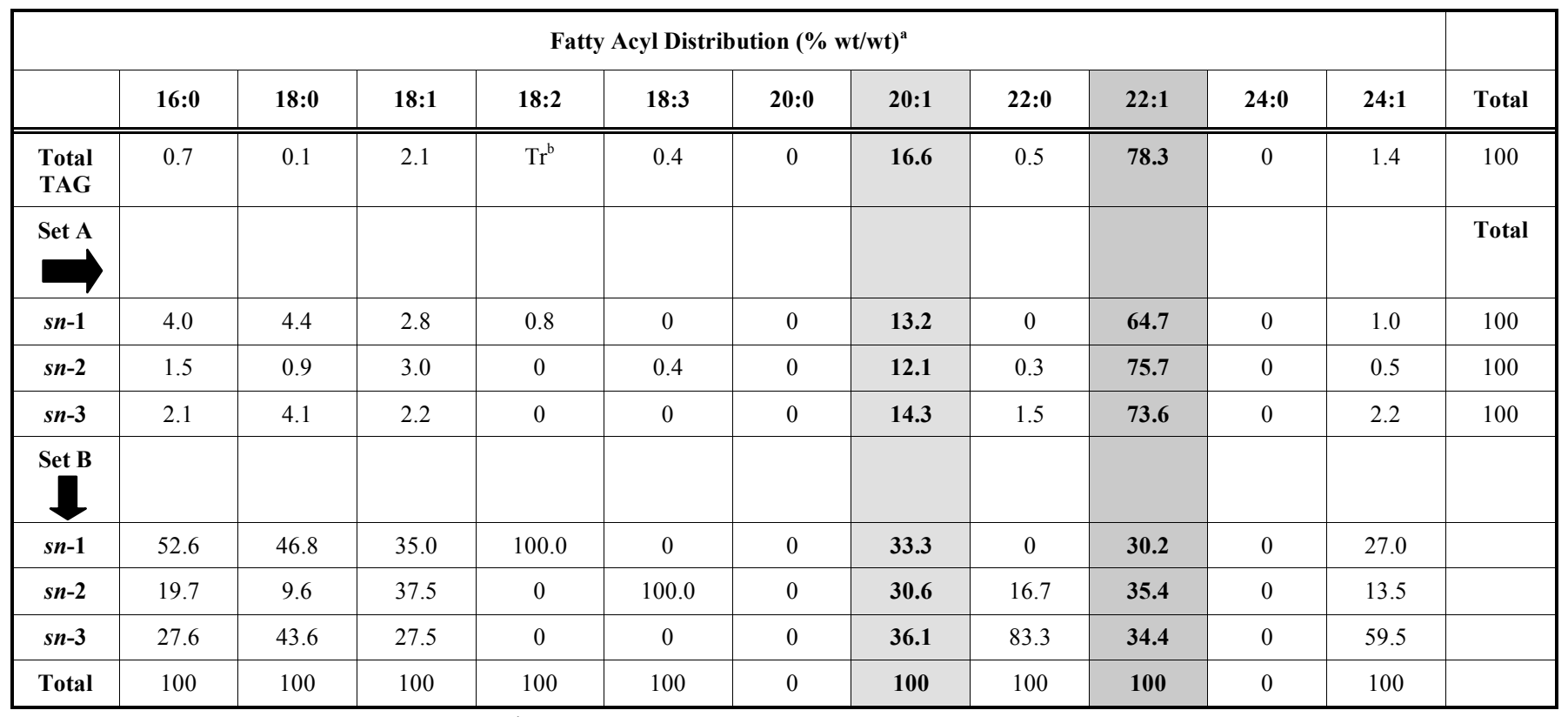

${ }^{a}>95 \%$ of total GC FAME peaks accounted for in all cases. ${ }^{b} \operatorname{tr}=<0.05 \% \mathrm{wt} / \mathrm{wt}$; minor traces of other fatty acyl moieties not shown.

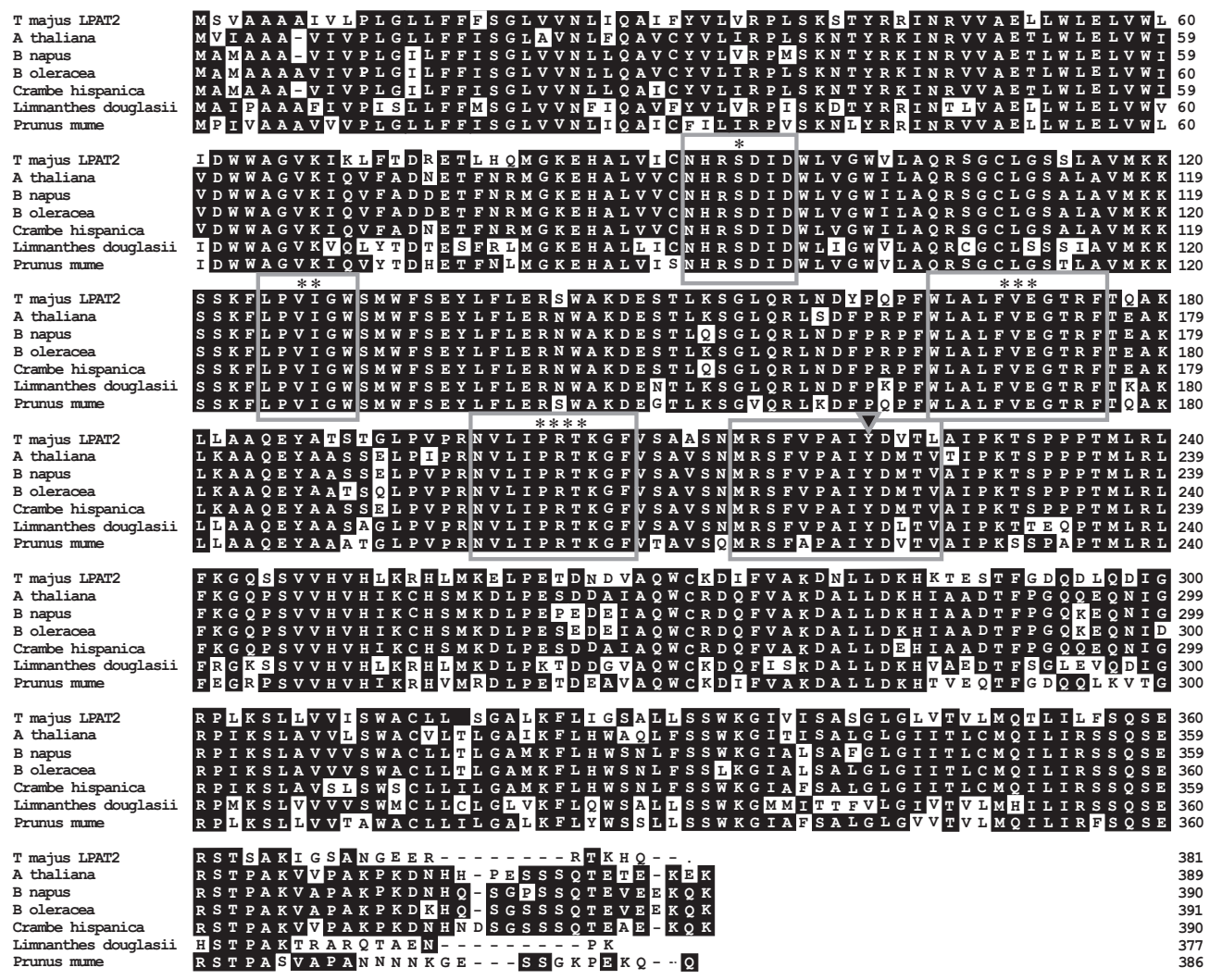

Fig. (2). Comparison of TmLPAT2 predicted amino acid sequence with that of other LPATs: Arabidopsis thaliana (NM_115625.pro); Brassica napus (Q9XFW4.pro); Brassica oleracea (Q6IWY1.pro); Crambe hispanica (ABN09946.pro); Limnanthes douglasii (CAA88620.pro); Prunus mume (BAE48660.pro). Box I-IV motifs are conserved among related LPATs in various plant species [11]: Box I (*) $=$ a conserved MBOAT motif (NHXXXXD): NHRSDID in position $91-97$ [33]; Box II $(* *)=$ LPVIGW; Box III $(* * *)=$ the "EGT" box; Box IV $(* * * *)=$ NVLIPRTKGF. There is also a putative tyrosine phosphorylation site $\mathrm{R}^{215}-(\mathrm{X})_{6}-\mathbf{Y}^{\mathbf{2 2 2}}-(\mathrm{X})_{4}-\mathrm{A}^{227}$ (a characteristic motif consisting of an arginine at position -7 , tyrosine at position 0 , and glycine/alanine at position +5 [34]. The arrow designates the critical tyrosine residue 


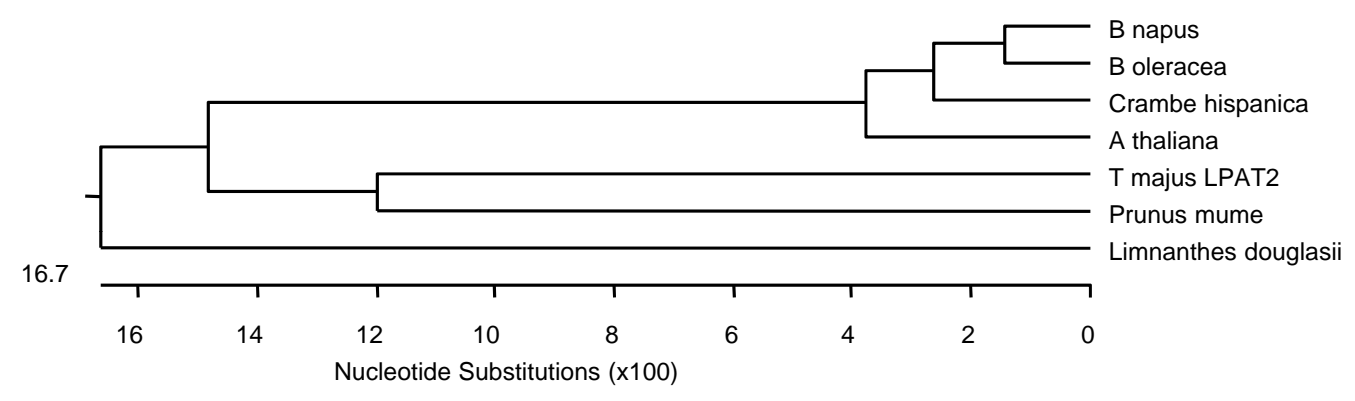

Fig. (3). Phylogenetic tree comparing the LPAT2s cited in Fig. (2).

Box II is a LPVIGW motif, Box III is a "EGT" box, Box IV is a NVLIPRTKGF motif, and the final box with an arrow is a putative tyrosine phosphorylation site $\mathrm{R}^{215}-(\mathrm{X})_{6}-\mathrm{Y}^{222}-(\mathrm{X})_{4}$ $\mathrm{A}^{227}$, which is a characteristic motif consisting of an arginine at position -7 , tyrosine at position 0 , and glycine/alanine at position +5 [34]. The sequence FVEGTR(F/S) is conserved among these plant LPAT2s as well as the E. coli LPAT (plsC; $[35,36]$ and the Saccharomyces cerevisiae LPAT (SLC1; [37]). Among more than half the dozen plant LPAT2s depicted in the phenogram in Fig. (3), the TmLPAT2 showed high homologies (74\%-79\%). The TmLPAT2's closest homolog was to a LPAT from Prunus mume (79.5\%, GenBank accession number BAE48660). High identity was observed with LPAT2s from Limnanthes douglassii $(75.6 \%$, GenBank accession number CAA88620), Crambe hispanica (75.3\%, GenBank accession number ABN09946), B. napus (75.3\%, GenBank accession number Q9XFW4), A. thaliana (74.7\%, GenBank accession number NM_115625), and B. oleracea (74.8\%, GenBank accession number Q6IWY1). It is interesting that the closest homolog, P. mume, has kernel oil containing only oleic (58-74\%), linoleic (20-34\%) and palmitic (4-7\%) acids, but virtually no VLCFAs (http:// www.woodlandnut.com/apricot.html).

Southern analyses, using restriction enzymes that do not cut within the region recognized by the probe and high stringency washings, resulted in a simple banding pattern with one single band of high intensity suggesting that there is only one copy of the LPAT2 gene in the nasturtium genome (Fig. 4A).

Northern analyses (Fig. 4B) showed that the gene was expressed in all tissues tested, including roots, stems, leaves, flowers, and at all three developmental embryo stages tested (with the mid-developing stage having the strongest embryo expression). While unusual, this ubiquitous, constitutive expression pattern is similar to that reported previously [11] for an ER-based LPAT2 essential for female but not male, gametophyte development in Arabidopsis. However, the current pattern is distinct from Limnanthes which is known to have both an embryo-specific LPAT2 gene and a constitutivelyexpressed LPAT1 [20]. Indeed, most LPAT2s utilizing unusual fatty acids are seed-specific [10]. The current finding represents, to our knowledge, the first oilseed LPAT2 utilizing unusual fatty acids that is expressed ubiquitously, with expression levels even higher in vegetative tissues, than in developing seed. The vegetative tissues do not synthesize or accumulate erucic acid, so this suggests that the TmLPAT2 enzyme is promiscuous and accepts a wide range of acyl groups.
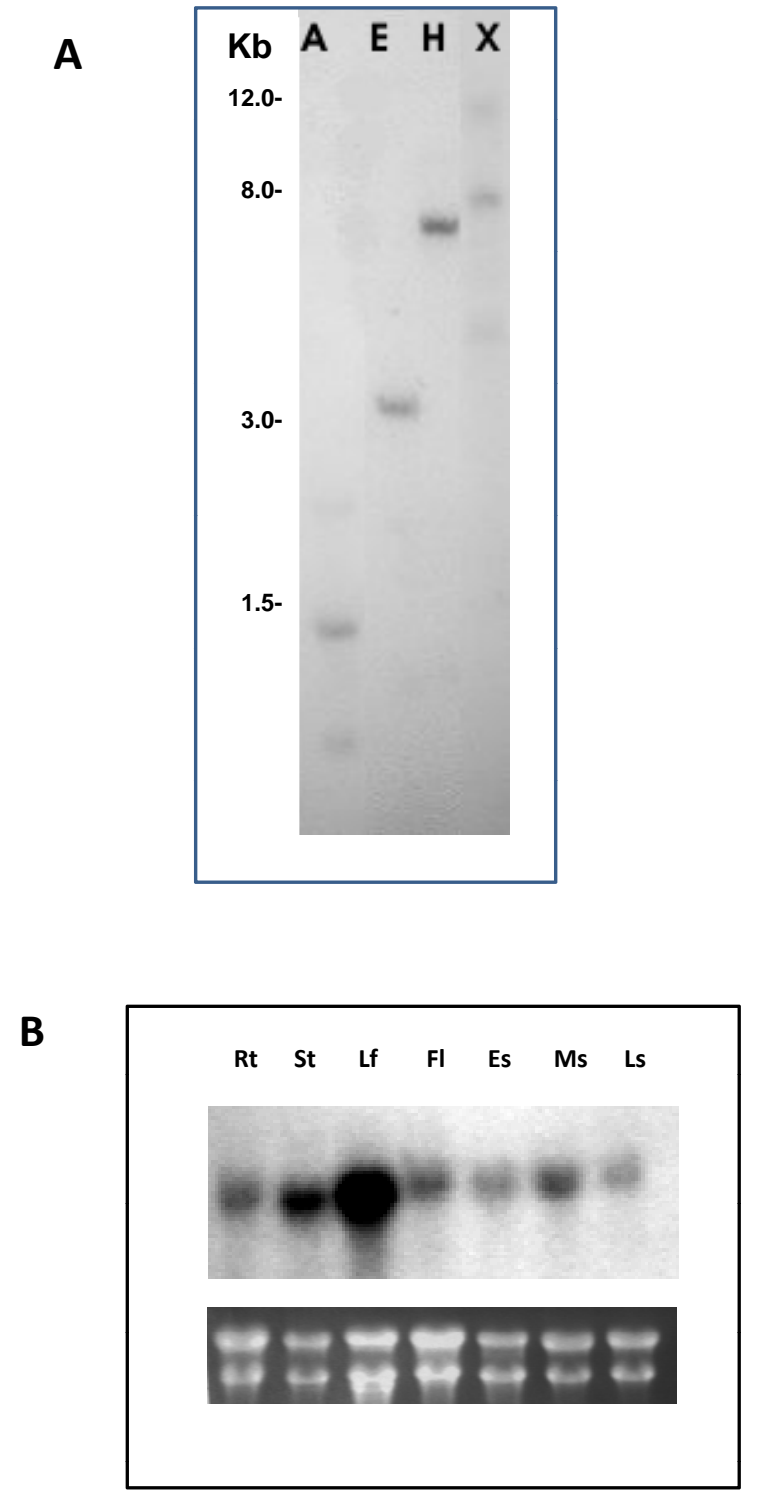

Fig. (4). (A) Southern blot analysis of TmLPAT2. A ${ }^{32} \mathrm{P}$-labeled probe from the 5' end region of the TmLPAT2 gene was hybridized to $15 \mathrm{ug}$ of total genomic DNA from leaves of T. majus digested with restriction enzymes AseI (A), EcoRI (E), HindIII $(\mathrm{H})$ and XhoI (X) and run along a $1 \mathrm{~Kb}$ ladder $(\mathrm{L})$. (B) Northern blot of the TmLPAT2 expression in various tissues of garden nasturtium. Top panel: Total RNA was isolated from root (Rt), stem ( $\mathrm{St})$, leaf (Lf), flower (Fl) and early (Es), mid- (Ms) and late (Ls) developing seed tissues, blotted and probed with ${ }^{32}$ P-labeled TmLPAT2 cDNA. Bottom panel: The amount of RNA loaded per line was calibrated by the relative ethidium bromide staining of the ribosomal RNA bands. 
Study of TmLPAT2 and AtLPAT2 HeterologouslyExpressed in the Yeast $L P A T$ (slc $\Delta$ ) Deletion Mutant Y03749

The TmLPAT2 heterologously expressed in the yeast $S L C 1^{-}$mutant was able to incorporate $22: 1$ into the $s n-2$ position of 18:1-LPA from 22:1-CoA (Fig. 5). In following the induction of gene expression $(8,16,24,48 \mathrm{hr}$; data not shown), the strongest expression was observed after 24 hours of induction. In fact, in the presence of 18:1-LPA as an acceptor, the heterologously-expressed TmLPAT2 was able to utilize a range of acyl-CoA substrates (Fig. 6A) including 16:0-CoA, 18:1-CoA or 20:1-CoA, with about equal efficiency. Erucoyl-CoA was also a capable acyl donor, with the activity being about $55 \%$ of that observed with oleoyl-CoA. This relative acyl preference profile for the recombinant TmLPAT2 is similar to that reported by Brough et al., [20] using recombinant $L$. douglasii LPAT2 expressed in an $E$. coli LPAT $^{-}$mutant strain JC201; in that study, the $L$ douglasii LPAT2 22:1-CoA activity was approx 30\% of that observed with oleoyl-CoA. The TmLPAT2 was also able to use 22:1-LPA as an acceptor in the presence of either 18:1-CoA or 22:1-CoA as the acyl donor; the 22:1-CoA LPAT activity with $22: 1-L P A$ was about $20 \%$ of that observed with the 18:1-CoA donor (Fig. 6B). In vivo upon biosynthesis of oil in developing nasturtium seeds, trierucin is the major product. Thus the latter in vitro result with the TmLPAT may underestimate what is possible with this enzyme in vivo: Indeed, since 22:1-CoA is the dominant acyl-CoA species in the developing nasturtium embryo, the resultant TAGs should have erucic at all three positions even if the activity with 22:1-CoA LPA with 22:1-LPA as acceptor was lower compared to the 18:1-CoA LPAT activity with 22:1-LPA as the acceptor in vitro.

In contrast, while the heterologously-expressed $A t$ LPAT2 was able to use oleoyl-CoA, it was unable to use erucoylCoA significantly, a trend identical to that observed with a $B$. napus Topas LPAT2 positive control system wherein erucoyl-LPAT activity was less than $2 \%$ of oleoyl-LPAT activity. This trend also agrees with our past biochemical studies [26]. In comparing the TmLPAT2 and $A t$ LPAT2 activities at maximal heterologous expression in yeast, the specific activity of the expressed TmLPAT2 with oleoyl-CoA + 18:1-LPA as substrates was approximately 4-fold higher than the corresponding activity with $A t$ LPAT2 (Fig. 6C). The reason for this markedly higher activity of the TmLPAT2 is currently unclear, but may point to the preference for genetically over-expressing the TmLPAT2 to enhance flux through the Kennedy pathway and into oil. Such experiments have been successful with the yeast $S L C 1-1$ mutated LPAT gene [44].

While there has recently been another lyso-phospholipid acyltransferase discovered in yeast (ScLPLAT), it differs from the specific lyso-phosphatidic acid acyltransferase that is encoded by SLC1 in that it cannot efficiently use lysophosphatidic acid produced by acylation of glycerol-3phosphate in vitro; rather, it prefers to acylate lysophosphatidylcholine (LPC) [38]. Under our assay conditions, in the control Y03749 LPAT $^{-}$mutant transformed with empty plasmid, wherein the ScLPLAT activity is still present, there was low but significant LPLAT activity with

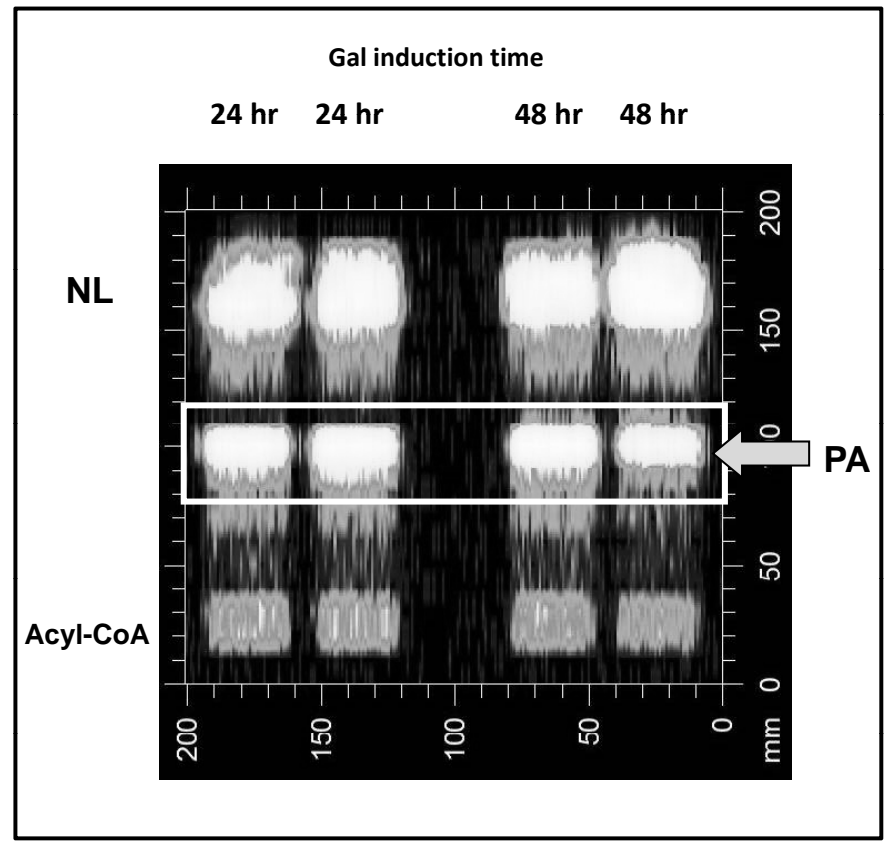

Fig. (5). Radiogram of TLC plate of the total lipid extract from LPAT assay of protein fraction from 24 or 48 -hour induced cultures of yeast mutant (slcA) Y03749 expressing recombinant TmLPAT2. Assays were conducted in the presence of 18:1-LPA $+\left[1-{ }^{14} \mathrm{C}\right] 22: 1-\mathrm{CoA}$. The radiolabelled lipid bands, especially the phosphatidic acid (PA) band (shown by an arrow) were isolated by TLC on silica G plates developed in ethylacetate: iso-octane: acetic acid $(45: 10: 10 \mathrm{v} / \mathrm{v} / \mathrm{v})$ in 1 dimension and then scanned on a Bioscan AR-2000 radio-TLC scanner using Win-Scan 2DC software (Bioscan Inc., Washington DC, USA). To quantify the radioactivity and calculate enzyme activity, the individual silica bands were scraped, $5 \mathrm{~mL}$ of Aquasol-2 (DuPont) scintillation solvent added to the silica, and the level of ${ }^{14} \mathrm{C}$ measured on a scintillation counter. The arrow shows the radiolabeled $s n-1 \quad 18: 1 / s n-2\left[1-{ }^{14} \mathrm{C}\right] 22: 1$ PA product. ${ }^{14} \mathrm{C}-\mathrm{NL}=$ neutral lipid (primarily FFA); residual ${ }^{14} \mathrm{C}$ erucoyl-CoA is at the origin. The expression of the recombinant TmLPAT2 enzyme reached a maximum at $24 \mathrm{hr}$ of Gal induction in the transformed yeast host. 
18:1-LPA + 18:1-CoA; the results shown in Fig (6) are corrected for this background activity. In addition, in the Y03749 LPAT $^{-}$mutant transformed with empty plasmid, significant LPCAT activity was observed as expected, with 18:1-CoA + 18:1-LPC, but not with 22:1-CoA + 18:1-LPC (Fig. 6D). Neither was there acylating activity observed when LPE, LPS or LPI were provided as acyl acceptors (data not shown). This clearly confirms that the T. majus erucoylCoA:LPAT activity expressed in the Y03749 LPAT $^{-}$mutant background is not due to the ScLPLAT.

Our findings indicate that the cloned and ectopicallyexpressed TmLPAT2 gene encodes a product which can utilize a number of acyl-CoA donors to acylate the $s n-2$ position of LPA, including erucoyl-CoA, at a rate of the same order of magnitude as that observed with oleoyl-CoA. The TmLPAT2 is not highly acyl-CoA-specific.

Predictions of acyl specificity of LPATs have arisen primarily from biochemical studies involving LPAT enzyme assays of microsomal fractions from developing seeds. Previous studies of the LPATs from a number of oilseeds had suggested that the TmLPAT was not involved in synthesis of trierucin because microsomal preparations from developing T. majus embryos exhibited little or no LPAT activity with erucoyl-CoA $[16,39]$. In contrast, our in vitro study showed that activity of erucoyl-CoA LPAT was present in developing nasturtium embryos [26]. However, short of cloning and expressing a candidate gene, biochemical evidence can be misleading as to how it will perform in vivo: Case in point, we ourselves reported, based on microsomal LPAT enzyme assays of a high erucic $B$. oleracea landrace, that the LPAT could utilize erucoyl-CoA in vitro, [26]. However, its capacity to do so in vivo proved negative once we cloned the gene and manipulated the gene in 2004 [Mietkiewska et al, 2004; Brassica oleracea acyl-CoA:1-acylglycerol-3-phosphate acyltransferase mRNA, complete cds. GenBank Accession No. AY616009)]; Upon expression in Arabidopsis, the actual capacity of the $B$. oleracea LPAT to insert erucic acid
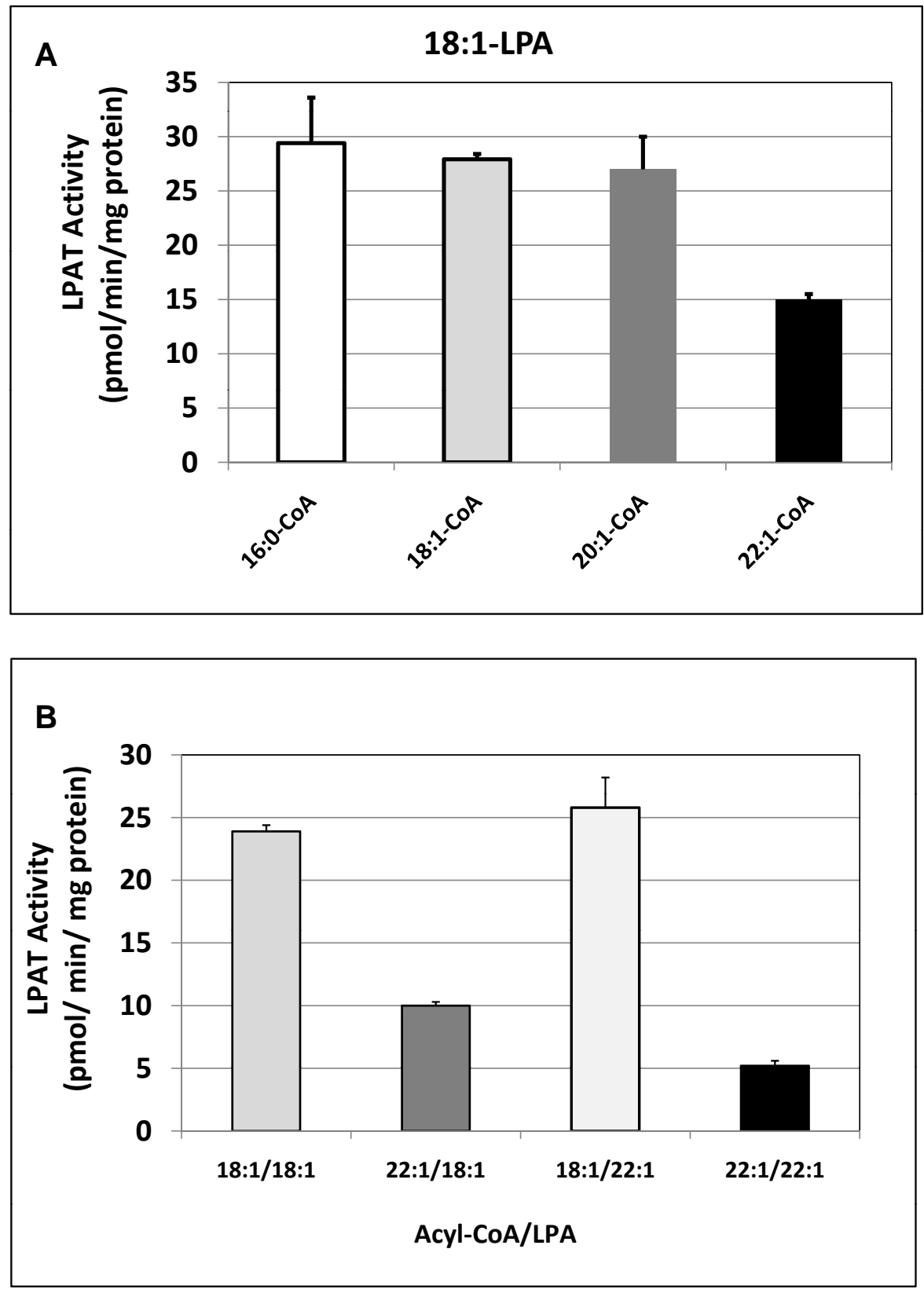


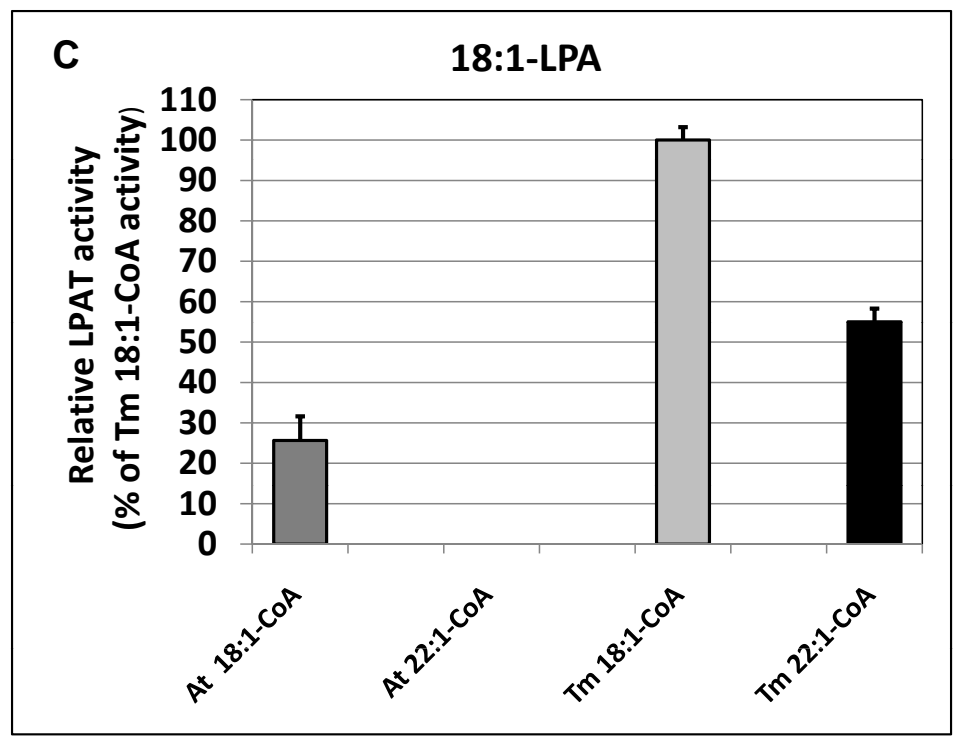

Fig. 6. Contd....

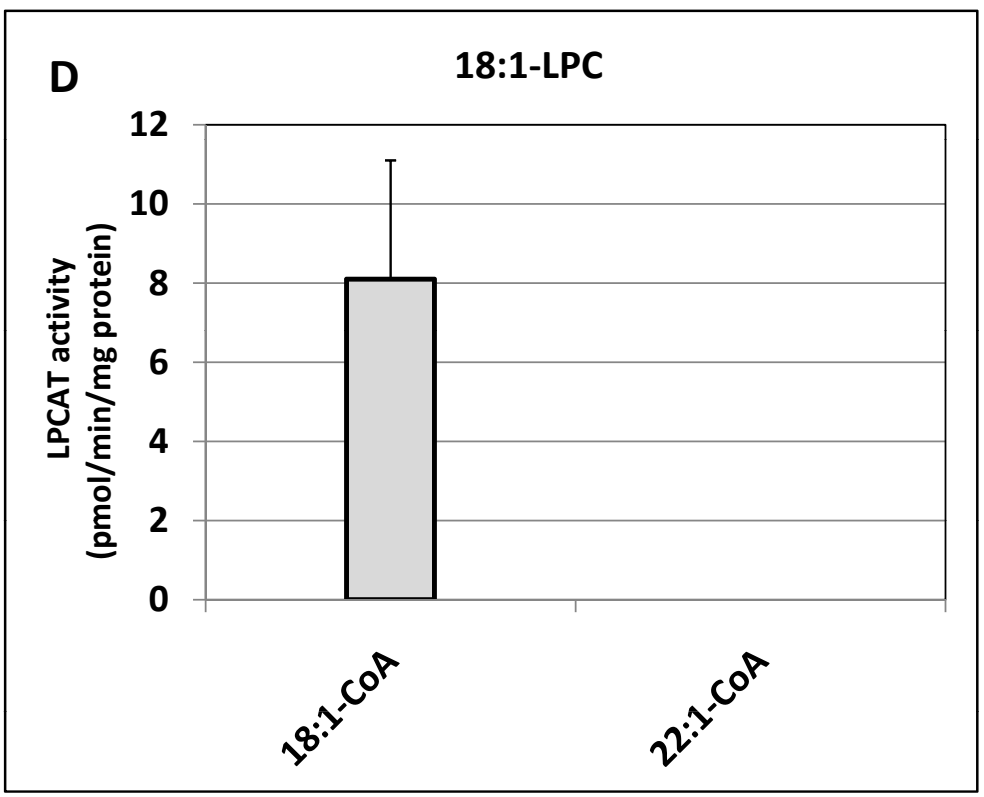

Fig. (6). LPAT activities measured in $10 \mathrm{~K}$ pellet fraction prepared from lysates of yeast $L P A T-\left(S L C 1^{-}\right)$mutant (slc $\triangle$ ) Y03749 transformed with the TmLPAT2: (A) Comparison of LPAT2 activities in the presence of 18:1-LPA and either ${ }^{14} \mathrm{C} 16: 0-18: 1-, 20: 1-$ or $22: 1-C o A$. (B) Comparison of TmLPAT2 activities in the presence of 18:1-LPA, and either ${ }^{14} \mathrm{C} 18: 1-\mathrm{CoA}$ or ${ }^{14} \mathrm{C} 22: 1-\mathrm{CoA}$; and $22: 1 \mathrm{LPA}$ and either ${ }^{14} \mathrm{C}$ 18:1-CoA or ${ }^{14} \mathrm{C} 22: 1-\mathrm{CoA}$ (C) Comparison of recombinant TmLPAT2 (Tm) and AtLPAT2 (At) activities with 18:1-LPA and either ${ }^{14} \mathrm{C} 18: 1-$ CoA or ${ }^{14} \mathrm{C}$ 22:1-CoA; (D) LPLAT (LPCAT) activities in the TmLPAT2-transformed Y03749 lysate in the presence of 18:1-LPC and either ${ }^{14} \mathrm{C}$ 18:1-CoA or ${ }^{14} \mathrm{C} 22: 1-\mathrm{CoA}$. All activities are corrected for the low background activity of labeled PA displayed in pYES plasmid only transformant lysates ( $c a 1 \mathrm{pmol} / \mathrm{min} / \mathrm{mg}$ pr; presumably due to the low but measureable activity of the yeast LPLAT with an LPA substrate).

into the $s n-2$ position of TAGs was nil (Taylor et al., 2005, unpublished).

Highly homologous predicted protein sequences can encode members of the same family of enzymes which nonetheless have widely varying catalytic substrate specificities not apparent from their primary sequences or even based on in vitro biochemical analyses. Indeed, of the LPAT2s listed in Fig. 3 using homology algorithms, until the present study, only those from Limnanthes spp have been shown to possess erucoyl-CoA LPAT activity [21]. Yet the homology scores are very close: For example, the L. douglasii sequence is known to be an erucoyl-utilizing LPAT2 while the albeit homologous $B$. napus and Arabidopsis LPAT2 sequences at $75 \%$ identity, do not encode enzymes with any capacity to utilize erucoyl moieties; the $T$. majus LPAT2 is negligibly more homologous to the Limnanthes LPAT2 at 75.6\% identity than it is to the B. napus LPAT2 at $75.3 \%$ identity. Thus, the selective characteristics of the T. majus and Limnanthes LPAT protein sequences that lead to erucoyl-CoA- utilizing capability are not currently understood. However, now having a second LPAT (T. majus) with this capability will provide an opportunity for more detailed comparative studies of 
motifs and secondary or tertiary structure which may define acyl donor and acceptor preferences.

\section{CONCLUSIONS}

In summary, our findings would suggest that $T m$ LPAT2 does indeed possess a strong capacity to utilize 22:1-CoA. Combined with other studies of the biosynthesis of TAGs containing sn-2 22:1 in T. majus [40-42], it appears that such TAGs are probably synthesized via the Kennedy pathway and not via acyl exchange at the $s n-2$ position of DAGs and TAGs as suggested previously [39]. Thus, in all oilseeds studied thus far that accumulate TAGs containing VLCMFAs, the data are consistent with VLCMFA biosynthesis by elongation of oleoyl moieties to give VLCMFACoAs, which are then used in the synthesis of TAGs via the Kennedy pathway acyltransferases.

We propose that the capacity to acylate the glycerol backbone with erucoyl moieties at the $s n-2$ position, is a very valuable property for molecular breeding of high erucic acid plants. For example, the expression of the TmLPAT2 clone in high erucic Brassicaceae (e.g. the high erucic B. carinata lines co-expressing the Crambe KCS and an RNAi-silenced B. carinata FAD 2 [43] or the Cardamine graeca KCS [45], will be capable of enhancing the overall proportions of VLCFAs in the $s n-2$ position of TAGs and increase the probablility of producing trierucin or trinervonin, respectively. In addition, the transgenic over-expression of the TmLPAT2 in the Brassicaceae may afford improvements in oil content in a manner not dissimilar to that already shown for ectopic expression of the yeast SLC1-1 gene [44]). Accordingly, transformation experiments are currently underway in our lab to test these hypotheses.

\section{ACKNOWLEDGEMENTS}

The authors acknowledge the contribution of Dr. E. Mietkiewska to preliminary T. majus cDNA library construction work. The 22:1-LPA was kindly provided as a gift from Dr. S. Stymne. The authors also thank Drs. M. Smith and J. Zou for their critical reviews of the manuscript. This is National Research Council of Canada Publication No. 50151 .

\section{ABBREVIATIONS}

\begin{tabular}{|c|c|}
\hline A thal & $=($ Arabidopsis thaliana $)$ \\
\hline $\mathrm{CoA}$ & $=$ Co-enzyme $\mathrm{A}$ \\
\hline cDNA & $=$ Complementary DNA \\
\hline EST & $=$ Expressed sequence tag \\
\hline LPA & $=L y$ so-phosphastidic acid \\
\hline LPCAT & $\begin{array}{l}=\text { Lyso-phosphatidylcholine } \\
\text { ferase }\end{array}$ \\
\hline LPAT 2 & $\begin{aligned}= & \text { Lyso-phosphastidic acid acyltransferase } \\
& 2 \text { (E.C. EC 2.3.1.51), sn-2 acyltrans- } \\
& \text { ferase }\end{aligned}$ \\
\hline MBOAT & $=$ Membrane bound $O$-acyltransferase \\
\hline PA & $=$ Phosphastidic acid \\
\hline$S L C 1-1^{-}$ & $=\begin{array}{l}\text { Yeast lyso-phosphastidic acid acyl- } \\
\text { transferase deletion mutant, slc } \Delta\end{array}$ \\
\hline
\end{tabular}

T. majus

$=$ Tropaeolum majus (garden nasturtium)

TAG

VLCFA

$=$ Triacylglycerol

22:1 Erucic acid = all fatty acids are similarly designated (22:1 c13;

$22: 1 \Delta 13)$ $\mathrm{x}: \mathrm{y}$, carbon chain length: number of double bonds

\section{REFERENCES}

[1] Han J, Luhs W, Sonntag K, et al. Functional characterization of $\beta$ ketoacyl-CoA synthase genes from Brassica napus L. Plant Mol Biol 2001; 46: 229-39.

[2] Sonntag NOV. Industrial utilization of long-chain fatty acids and their derivatives. In: Kimber DS, McGregor DI, Eds. Brassica Oilseeds. Oxon, UK: CAB International 1995; 339-52.

[3] Scarth R, Tang J. Modification of Brassica oil using conventional and transgenic approaches. Crop Sci 2006; 46: 1225-36.

[4] Leonard EC. High-erucic vegetable oils. Indus Crops Prod 1993; 1: 119-23.

[5] Derksen JTP, Cuperus FP, Kolster P. Paints and coatings from renewable resources. Indust Crops Prod 1995; 3: 225-36.

[6] Puyaubert J, Garcia C, Chevalier S, Lessire R. Acyl-CoA elongase, a key enzyme in the development of high-erucic acid rapeseed? Eur J Lipid Sci Technol 2005; 107: 263-67.

[7] McVetty PBE, Scarth R. Breeding for improved oil quality in Brassica oilseed species. J Crop Prod 2002; 5: 345-69.

[8] Taylor DC, MacKenzie SL, McCurdy AR, et al . Stereospecific analyses of triacylglycerols from high erucic brassicaceae: detection of erucic acid at the $s n-2$ position in $b$. oleracea 1 . Genotypes. J Am Oil Chem Soc 1994; 71: 163-67.

[9] Stymne S, Stobart AK. Triacylglycerol biosynthesis. In: Stumpf PK, Ed. The Biochemistry of Plants, Lipids: Structure and Function., New York: Academic Press 1987; 9: pp. 114-75.

[10] Weselake RJ. Storage lipids. In: Murphy DJ, Ed. Plant Lipids:Biology,Utilization and Manipulation. Oxford, UK: Blackwell Publishing 2005; 162-21.

[11] Kim HU, Li Y, Huang AHC. Ubiquitous and endoplasmic reticulum-located lysophosphatidyl acyltransferase, lpat2, is essential for female but not male gametophyte development in arabidopsis. Plant Cell 2005; 17: 1073-89.

[12] Oo K-C, Huang AHC. Lysophosphatidate acyltransferase activities in the microsomes from palm endosperm, maize scutellum, and rapeseed cotyledons of maturing seeds. Plant Physiol 1989; 91: 1288-95.

[13] Bernerth R, Frentzen M. Utilization of erucoyl-COA by acyltransferases from developing seeds of Brassica napus (L.) involved in triacylglycerol biosynthesis. Plant Sci 1990; 67: 21-8.

[14] Taylor DC, Thomson LW, MacKenzie SL, Pomeroy MK, Weselake RJ. Target Enzymes for Modification of Seed Storage Lipids. In: McFerson JR, Kresovich S, Dwyer SG, Eds. Sixth Crucifer Genetics Workshop Proceedings. Cornell University, Geneva, NY: USDA-ARS Plant Genetic Resources Unit 1990; pp. 38-39.

[15] Taylor DC, Barton DL, Rioux KP, et al. Biosynthesis of acyl lipids containg very-long chain fatty acids in microspore derived and zygotic embryos of Brassica napus L. cv. Reston. Plant Physiol 1992; 99: 1609-18.

[16] Cao YZ, Oo KC, Huang AHC. Lysophosphatidate acyltransferase in the microsomes from maturing seeds of meadowfoam. (Limnanthes alba). Plant Physiol 1990; 94: 1199-06.

[17] Lohden I, Bernerth R, Frentzen M. Acyl-CoA:1-acylglycerol-3phosphate acyltransferase from developing seeds of Limnanthes douglasii (R.Br.) and Brassica napus (L.) In: Quinn PJ, Harwood JL, Eds. Plant Lipid Biochemistry, Structure and Utilization London: Portland Press 1990; pp. 175-77.

[18] Peterek G, Schmidt V, Wolter FP, Frentzen M. Approaches for cloning 1-acylglycerol acyltransferase from oilseeds. In: Cherif A, Ed. Metabolism, Structure and Utilization of Plant Lipids., Tunis, Tunisia: CNP Press 1992; pp. 401-04.

[19] Murphy DJ, Richards D, Taylor R, et al. Manipulation of seed oil content to produce industrial crops. Indust Crops Prod 1994; 3: 1727. 
[20] Brough CL, Coventry JM, Christie WW, et al. Towards genetic engineering of triacylglycerols of defined fatty acid composition: Major changes in erucic acid content at the $s n-2$ position affected by the introduction of a 1 -acyl-sn-glycerol-3-phosphate acyltransferase from Limnanthes douglasii into oil seed rape. Mol Breeding 1996; 2: 133-42.

[21] Lassner MW, Levering CK, Davies HM, Knutzon DS. Lysophosphatidic acid acyltransferase from meadowfoam mediates insertion of erucic acid at the $s n-2$ position of triacylglycerol in transgenic rapeseed oil. Plant Physiol 1995; 109: 1389-94.

[22] Hanke C, Wolter FP, Coleman J, Peterek G, Frentzen M. A plant acyltransferase involved in triacylglycerol biosynthesis complements an Escherichia coli sn-1-acylglycerol-3-phosphate acyltransferase mutant. Eur J Biochem 1995; 232: 806-10.

[23] Weier D, Hanke C, Eickelkamp A, et al. Trierucoylglycerol biosynthesis in transgenic plants of rapeseed (Brassica napus L.). Lipid Fett 1997; 99: 160-65.

[24] Nath UK, Wilmer JA, Wallington EJ, Becker HC, Möllers C. Increasing erucic acid content through combination of endogenous low polyunsaturated fatty acids alleles with $L d-L P A A T+B n-f a e 1$ transgenes in rapeseed (Brassica napus L.). Theor Appl Genet 2009; 118: 765-73.

[25] Mietkiewska E, Giblin EM, Wang S, et al. Seed-specific heterologous expression of a T. majus FAE gene in Arabidopsis results in a dramatic increase in the proportion of erucic acid. Plant Physiol 2004; 136: 2665-75.

[26] Taylor DC, Barton DL, Giblin EM, et al. Microsomal lysophosphatidic acid acyltransferase from a brassica oleracea cultivar incorporates erucic acid into the $s n-2$ position of seed triacylglycerols. Plant Physiol 1995; 109: 409-20.

[27] Bonaldo MF, Lennon G, Soares MB. Normalization and subtraction: two approaches to facilitate gene discovery. Genome Res 1996; 6: 706-91.

[28] Altschul SF, Gish W, Miller W, Myers EW, Lipman DJ. Basic local alignment search tool. J Mol Biol 1990; 215: 403-10.

[29] Nakai K, Kanehisa M. A knowledge base for predicting protein localization sites in eukaryotic cells. Genomics 1992; 14: 897-11.

[30] Dellaporta L, Wood J, Hicks JB. Isolation of DNA from higher plants. Plant Mol Biol Rep 1983; 4: 19-21.

[31] Wang CS, Vodkin LO. Extraction of RNA tissues containing high levels of procyanidins that binds RNA. Plant Mol Biol Rep 1994; 12: $132-45$.

[32] Xu J, Francis T, Mietkiewska E, et al. Cloning and characterization of an acyl-CoA-dependent diacylglycerol acyltransferase 1 (DGAT1) gene from Tropaeolum majus, and a study of the functional motifs of the DGAT protein using site-directed mutagenesis to modify enzyme activity and oil content. Plant Biotechnol J 2008; 6: 799-18.
[33] Hofman K. A superfamily of membrane-bound O-acyltransferases with implications for wnt signaling. Trends Biochem Sci 2000; 25 : 111-2.

[34] Cooper JA, Esch FS, Taylor SS, Hunter T. Phosphorylation sites in enolase and lactate dehydrogenase utilized by tyrosine protein kinases in vivo and in vitro. J Biol Chem 1984; 259: 783541.

[35] Coleman J. Characterization of Escherichia coli cells deficient in 1acyl-sn-glycerol-3-phosphate acyltransferase activity. J Biol Chem 1990; 265: 17215-21.

[36] Coleman J. Characterization of the Escherichia coli gene for 1acyl-sn-glycerol-3-phosphate acyltransferase (plsc). Mo1 Gen Genet 1992; 232: 295-03.

[37] Nagiec MM, Wells GB, Lester RL, Dickson RC. A suppressor gene that enables Saccharomyces cerevisiae to grow without making sphingolipids encodes a protein that resembles an Escherichia coli fatty acyltransferase. J Biol Chem 1993; 268: 22156-63.

[38] Stahl U, Stalberga KS, Stymne S, Ronne H. A family of eukaryotic lysophospholipid acyltransferases with broad specificity. FEBS Letts 2008; 582: 305-09.

[39] Lohden I, Frentzen M. Triacylglycerol biosynthesis in developing seeds of Tropaeolum majus L. and Limnanthes douglasii R. Planta 1992; 188: 215-24.

[40] Pollard MR, Stumpf PK. Long chain $\left(\mathrm{C}_{20}\right.$ and $\left.\mathrm{C}_{22}\right)$ fatty acid biosynthesis in developing seeds of Tropaeolum majus, an in vivo study. Plant Physiol 1980; 66: 641-48.

[41] Murphy DJ, Mukherjee KD. Biosynthesis of very long chain monounsaturated fatty acids by subcellular fractions of developing seeds. FEBS Letts 1988; 230: 101-04.

[42] Whitfield H, Murphy DJ. Storage Lipid Synthesis in Nasturtium (Tropaeolum majus). In: Quinn PJ, Harwood, JL, Eds. Plant Lipid Biochemistry, Structure and Function. London: Portland Press 1990; pp. 225-7.

[43] Mietkiewska E, Hoffman TL, Brost JM, et al. Hairpin-RNA mediated silencing of endogenous FAD2 gene combined with heterologous expression of Crambe abyssinica FAE gene causes an increase in the level of erucic acid in transgenic Brassica carinata seeds. Mol Breeding 2008: 22: 619-27.

[44] Zou J, Katavic V, Giblin EM et al. Modification of seed oil content and acyl composition in Brassicaceae by expression of a yeast $s n-2$ acyltransferase gene. Plant Cell 1997; 9: 909-23.

[45] Taylor DC, Guo Y, Katavic V, Mietkiewska E, Francis T, Bettger W. In: Krishnan, HB, Ed. Modification of Seed Composition to Promote Health and Nutrition. Chapter 10: New Seed Oils for Improved Human and Animal Health and as Industrial Feedstocks: Genetic Manipulation of the Brassicaceae to Produce Oils Enriched in Nervonic Acid. Madison: ASA-CSSA- SSSA Publishing, WI 2009; pp 219-222. 